\title{
The Emergence and Growth Path of Shanzhai Firms
}

\author{
Jason Shay ${ }^{1}$, Peter Shieh ${ }^{2, *}$, Ming-Piao Tsai ${ }^{2}$, Hsiang-Jui Cheng ${ }^{3}$ \\ ${ }^{1}$ Boeing Global Services, Dallas, TX, USA \\ ${ }^{2}$ Department of Automation Engineering, National Formosa University, Yunlin, Taiwan \\ ${ }^{3}$ Taiwan Semiconductor Manufacturing Company, Ltd., Taichung, Taiwan \\ Received 11 April 2019; received in revised form 09 May 2019; accepted 26 June 2019
}

DOI: https://doi.org/10.46604/peti.2020.4064

\begin{abstract}
Shanzhai refers to a set of dynamic strategies for firms to grow out of counterfeiting. Shanzhai firms have traditionally been perceived as counterfeiters from the emerging economies producing cheap and low-quality products. This trend has changed in recent years when Shanzhai firms have grown into market leaders and have introduced leading technologies and applications. This paper focuses on the growth of Shanzhai firms by exploring how Shanzhai firms and Shanzhai industries emerged. We further investigate the context that supports the emergence of Shanzhai firms into market leaders. We leverage two case studies using the growth path of two market leaders in their respective industries to illustrate the two paths leading to the emergence of Shanzhai firms. We attempt to show that although Shanzhai firms start out with low legitimacy, these firms grow their legitimacy over time by building their core competitiveness in their respective industries.
\end{abstract}

Keywords: shanzhai, emerging economies, growth strategies, counterfeits

\section{Introduction}

Although imitation is considered as a type of strategy that firms often employee, counterfeit (imitations that infringe intellectual properties) is not generally accepted as a legitimate set of strategies for firms to practice [1-2]. However, it is intriguing that several firms considered as counterfeiters not too long ago have grown out of the emerging economies into big multinational firms and even market leaders. In this research, we attempt to address the concept of Shanzhai and the development path of Shanzhai firms leading them to become major players in their respective industries.

Originating from China, the concept of Shanzhai bloomed in the last two decades. Shanzhai refers to a set of dynamic strategies for firms to grow out of counterfeiting. Shanzhai is borrowed from the historical description of rural and unregulated villages in the mountains with their own leaders, armed forces, governance structures, and rules that are outside of the main country government regulations [3]. Thus, the term Shanzhai describes Chinese firms' practices of either counterfeiting or manufacturing closely imitated products and/or brands, evading laws and regulations. These firms are originally referred to as Shanzhai firms. Public perceptions of Shanzhai products are lookalike products with substandard quality that sell at lower prices [3]. Overall, public perceptions of Shanzhai have been negative over the past two decades. Yet the growth of Shanzhai firms has been unmistakable.

Although research on the growth of the firm in emerging economies has been expanding since the 1990s [4], the term Shanzhai had not appeared in the management literature until 2009 [5]. Until now, most literature focuses on distinguishing Shanzhai from counterfeit, or on investigating marketing strategies or consumer preferences. By definition, counterfeit is the

* Corresponding author. E-mail address: pimshieh@nfu.edu.tw

Tel.: +1-469-353-3647 
practice to capitalize on external competences without proper authorizations. If a firm develops own competences out of counterfeiting, it is a Shanzhai firm as opposed to a counterfeit firm. In the management literature, however, how Shanzhai firms develop and how such development change over time remains unclear. Therefore, we ask the following three interesting but underexplored questions: How do firms evolve into Shanzhai firms? What is the development path of Shanzhai firms? How do Shanzhai strategies help firms grow? We argue that the distinguishing factor between Shanzhai firms and counterfeiters lies in whether the firms ultimately build up their own core competencies to explore and exploit further business opportunities and markets or not.

Three contributions emerge. First, contributing to the Shanzhai literature, this research is among the first effort attempting to examine the emergence and impact of Shanzhai strategies. Second, we contribute to the emerging economies literature by examines the strategies help late-mover firms from emerging economies tap into mainstream technological developments and even become market-leading firms. Third, contributing to the innovation literature, this research shows how Shanzhai brings about another form of the innovative system.

\section{Original Equipment Manufacturers}

Since Shanzhai was brought into the management literature in 2009, current literature considers Shanzhai as a more dynamic strategy. In earlier stages of an industry lifecycle, many of the current Shanzhai firms started out as Original Equipment Manufacturers (OEMs) that build products designed and ordered by branding firms [3]. During this period, some OEM firms would sell - to separate markets and customers - substandard products and/or excess products intentionally produced [1]. As compared to non-OEM late-comer firms, these OEM firms would be at an advantage due to two reasons. First, these firms gained technological advantages by learning from branding firms. Some of these OEM firms even enjoyed financial and/or technological resources from branding firms to perform research and development, and to fulfill production tasks by branding firms. Second, OEM firms can defer such fixed costs as machinery on to products sold to branding firms, giving them pricing advantages when selling Shanzhai products on the markets.

More recently, after decades of outsourcing practices, multinational branding firms began the practice of multiple-sourcing [6]. While single-sourcing aims at sourcing some parts of production processes that are outside of firms' competences, multiple-sourcing allows branding firms to further reduce costs by allocating and reallocating procurement orders among multiple OEM firms. From branding firms' perspectives, multiple-sourcing defers a portion of transaction costs between branding firms and OEM firms, onto OEM firms by ensuring competition among OEM firms. However, from OEM firms' perspectives, multiple-sourcing dramatically increases OEM firms' costs and risks. For instance, if OEM firms lose orders, it is not likely they could quickly find alternative orders to fill their idle capacities that OEM firms prepared for the branding firms.

Due to the competition among OEM firms, many OEM firms are already equipped with product design capabilities and sufficient technological capabilities and production capacities to produce the final products that are transforming into Original Design Manufacturers (ODM) firm (OEM firms that also design for the branding firms). When OEM and ODM firms face over-competition or seek to find alternative methods to lower their dependence on branding firms, some OEM and ODM firms choose to cooperate with other branding firms. In addition, certain OEM and ODM firms begin introducing their own products into the market either through lookalike products or with new brand names owned by the OEM and ODM firms. The process of using the capabilities originally to serve the branding firms to divert into their own brands is Shanzhai. Fig. 1 illustrates the evolution of OEM and ODM firms into Shanzhai firms and then into branding firms.

In the case of Shanzhai, both routes exist. The first route begins with some OEM firms producing mass quantities of "white-tagged" products, which are products without a logo printed on them. When branding firms (which could be 
well-established firms or small new firms) come to these OEM firms, branding firms can order from these existing products. The OEM firms then print the branding firms' logos onto the products for sale. The second route begins when OEM firms introduce their own brands. These OEM firms would be likely to design their own products based on the designs that were originally used to produce the products of their clients. No matter which route the OEM firms choose, up to this point, these OEM firms could be doing the Shanzhai business in the grey area of counterfeit.

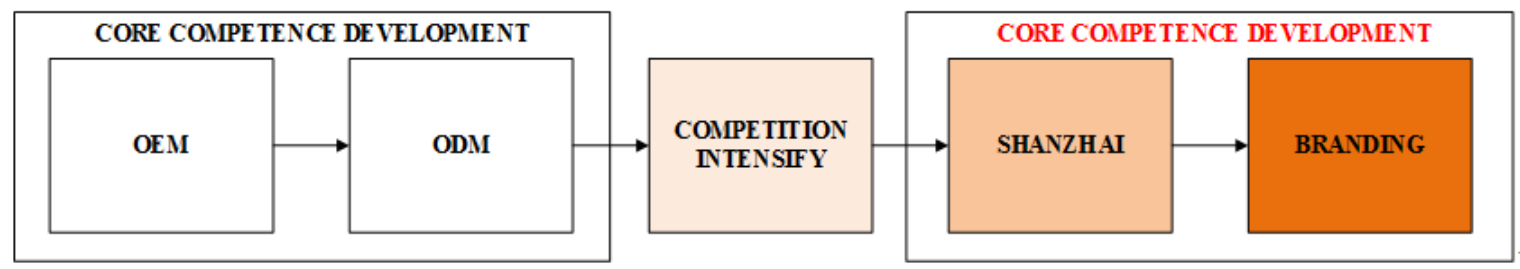

Fig. 1 The evolution of OEM and ODM firms into Shanzhai firms and then into branding firms

Traditional viewpoint on counterfeiting firms' points to the direction that counterfeiting firms do not really possess their own competences [7]. These counterfeiting firms merely imitate products and/or services on the market. More recently, scholars have challenged this perspective by highlighting that counterfeiting is a significantly big industry to be viewed as homogeneous [7]. Scholars try to introduce a more heterogeneous viewpoint in an attempt to account for different counterfeiting practices. Scholars were able to ascertain how counterfeiting firms specialize in different forms of counterfeiting strategies. Shanzhai firms would use some strategies that are classified as counterfeit (such as producing knockoffs or look-alike products) but Shanzhai firms also show capabilities to develop their own competencies [3, 8]. In sum, counterfeiting firms demonstrate the behavior to capitalize on other firms' competences. While it is observed that Shanzhai firms also demonstrate the same behavior, the difference between Shanzhai firms and counterfeit firms lies in the development of a firm's own competences. If a firm develops own competences out of counterfeiting, it is a Shanzhai firm as opposed to a counterfeit firm.

In the case of OEM firms' transformation, some OEM firms begin as almost counterfeiters, producing products similar to their branding-firm clients. With capabilities in both product and manufacturing processes, some of these OEM firms become Shanzhai firms when they deviate from the prevalent designs and begin introducing new products and/or serving different market niches as the prevalent products do.

Taiwanese bicycle manufacturing industry started out as OEM manufacturers that produce metal-based products, such as screws, bolts, and automotive parts. With these competencies in metal processing, companies first stepped into bicycle OEM industry in the late 1970s when the U.S.-based bicycle branding companies started placing bicycle orders with these OEMs. Since then, OEMs worked its way from pure OEM make-to-order to ODM that not only manufacture but also design bicycles for branding firms. The most important difference between OEMs and an ODMs lies in whether sourcing firms rely on the manufacturers in designing products (i.e. products are designed by sourcing firms or by the manufacturer). During those years as OEMs and ODMs, Taiwanese firms strengthened many of their competencies such as metal processing and manufacturing processes, and also gained many competencies such as metal structuring and material technologies.

In the later years of OEM/ODM and branding collaboration, branding firms had multiple OEM firms and ODM firms working competitively at the same time. Due to intense competition among branding firms' OEM and ODM partners, OEM and ODM firms need not only to fulfill procurement orders ahead of schedule, but for OEM and ODM firms had to do much more at their own expense, both in design and manufacturing aspects. For example, OEM and ODM firms had to prepare excess production capacities (free, of course) to what they needed to fulfill branding firms' orders. Furthermore, OEM and ODM firms had to perform research and development at their own costs on many aspects, such as improving production speed and quality and developing new materials and designing new structures for branding firms to develop its next products. When all of these competitive pressures kicked in, OEM and ODM firms that are out-competed would either be left out of the next 
procurement or receive less order from branding firm, and the OEM and ODM firms will be left with hefty fixed costs to allocate. Therefore, these OEM and ODM firms had to find other ways to cover these costs. With all the production and technological edge at hand, some OEM and ODM firms realized their risk of competition among their counterparts, and decided that there was a need to begin developing their own "bikes" and "brand" from what their learned from branding firms and from the capabilities it developed originally to serve branding firms [9].

From the case, we suggest that some Shanzhai firms and industries are actually fostered by branding firms themselves. Many suppliers began by serving mainstream branding companies. However, strategies by those branding firms, such as multiple-sourcing, caused many producers to be left out of the supply chain with full research and development (R\&D), technological, and production capabilities. These OEM firms have to come up with ways to fill their capacities when branding firms decide to the source of competing for OEM firms. Shanzhai has emerged as a major way to enable such growth.

\section{Technological Modularization}

For firms without an OEM background, past research finds a second path leading to Shanzhai. Researchers find that the ability in modularizing products and technologies in the value chain is one important factor distinguishing Shanzhai firms from pure counterfeiting firms $[8,10]$. Technology management literature provides modularization with a formal definition that modularization is a strategy used to efficiently organize complex products and processes [11]. Modularized systems are designed in such a manner that independent components are bundled up and work as an integrated whole unit [12]. According to Campagnolo et al. [13], the basic concept behind the modular design is to minimize interdependence between modules while maximizing interdependence within the modules. Scholars find that modular design is constructive in promoting new designs with a shorter production lead-time [3, 14-15].

In industries that are highly modularized, Shanzhai firms evolve along two paths: (1) Shanzhai firms assisting the formation of modularized technologies and (2) Shanzhai firms exploiting the benefits of modularized technologies. Modularization helps Shanzhai firms by providing them with flexibilities to change, such as adopting different technologies and adopting new technological developments. Scholars believe that Shanzhai firms could find and tap into a position in the already established value chains and that Shanzhai firms could bring new values to existing industries and value chains.

Scholars have identified that modularization is an important common ground for thriving Shanzhai industries [8, 10]. Shanzhai firms are likely to thrive around industries or value chains that are highly modularized. Modularization in industries or value chains often implies that the industries or value chains are highly specialized, allowing firms to find specific positions to tap into, rather than needing to have the whole set of know-how in the products or services. For example, during the early 2000s when smartphones were introduced, only firms that owned the whole set of technologies are able to design smartphones, such as Apple and Samsung. Approximately ten years later, smartphone components are modularized into sub-sections, such as camera modules, antenna modules, and touchscreen modules. Nowadays, relatively small and young companies entering the final product market can all procure components and/or modules sold by specialized module and/or component producers and integrate those components and modules into the prototypes of final products that are ready to be outsourced to professional manufacturers for mass production. Through modularization, technological entry barriers to the industry would be lowered that even small firms with much fewer resources and technological capabilities can now design smartphones and have the chances to actually introduce their products to the market [16].

In addition, the modularization also brings opportunities to Shanzhai firms by providing flexibilities for firms to produce final products. Technological modularization provides firms with more options in choosing and switching components. For example, the practice of pin-to-pin substitution (meaning that the Shanzhai product perfectly follows the prevalent designs for client firms to use) is a well-known strategy promoted by Shanzhai firms to urge branding firms to switch the components used 
in their products. Subsequent to modularization took place, unified standards and/or protocols would likely emerge, and the component manufacturers could follow the leading standards and/or protocols. Therefore, downstream firms would have more flexibility in switching among suppliers. In sum, modularization provides both existing and new firms with the flexibilities to introduce new designs cheaper and faster [15, 17-18].

So why do industries and value chains modularize? The current literature points toward two main reasons, technological complexity, and economies of scale $[8,10,17]$. Take the cell-phone camera module as an example. During the first couple of generations of Apple's iPhone, Apple designs everything ranging from processor chips to cameras, speakers, antennas, and so on. Over the years, iPhone designs evolve into being lighter and thinner and are more advanced. The components used in iPhones also evolve to be considerably more complicated than the designs and technologies behind the components used in iPhones developed beyond Apple's capabilities to handle. Nowadays, Apple depends on specialized firms to produce modularized components for Apple to put into its iPhone designs. While Apple is an expert in designing smartphones, it would be challenging for Apple to be specialized in all the technologies required to design entire smartphones.

At the same time, the economy of scale could be demonstrated by knowing that when smartphones become smaller, the manufacturing and assembling processes become increasingly complicated. It would take several significantly expensive and specialized machinery (that may not be useful in producing any other products) to produce camera modules or to assemble components into the final products. It is practically impossible for Apple to own all the technologies and machinery to make iPhone end-products. Therefore, ultimately Apple would realize that there is a need to design their products based on modularized components that they can outsource to specialized manufacturers for production. This is also the first source of how Shanzhai firms emerge out of technological modularization, by assisting technological modularization in the industries.

In this section, we demonstrate the second type of Shanzhai using the case of some Taiwanese and Chinese IC designing companies. These companies start out using counterfeit strategies, imitating the market leaders' designs, but some of them are now emerging as a competitor to leaders in low-end smartphone chipsets markets. Most of these latecomers were IC designer and IC service provider under IC OEM firm. These firms were firms that are very closely working with different streams of IC design technologies and is very flexible in making adjustments according to their clients' designs. Figure 2 illustrates how technological modularization induces the formation of Shanzhai firms.

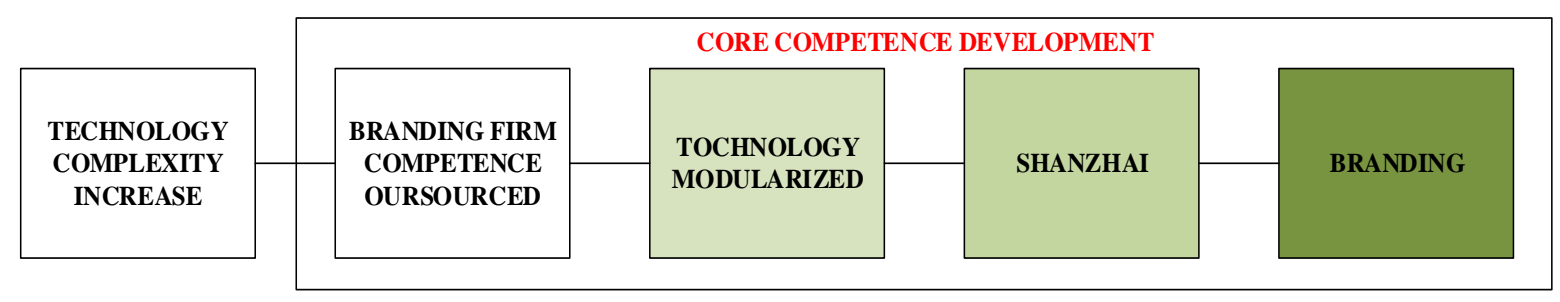

Fig. 2 Technological modularization induces the formation of Shanzhai firms

After leaders began to dominate the smartphone processor market, latecomers began to follow leaders from generation, structure, to specifications that leaders put on their processor chips. Latecomers introduce these processor chips not only to small smartphone companies but also to big companies as a cheap alternative for their lower-end smartphones. Furthermore, latecomers began packaging complementary components relating to processor chips into chipsets. This way, latecomers further helped smaller companies by reducing the complexities for firms to design smartphones. Since processor chipsets are the "hearts" to smartphones, by taking the burden to design processor chips out of smartphone designers, latecomers dramatically lowered entry barriers for firms to design smartphones. More recently, latecomers work closely with small smartphone companies in customizing specialized processor chips. [3, 8, 10,19]. This way, these latecomers gain their market by further reduce entry barriers to late-coming smartphone designers.

From the example of IC designers, it would not be hard to tell the differences between pure counterfeit firms from Shanzhai firms. While pure counterfeit firms only copy and sell branding firms' products, Shanzhai firms may start out similar 
to counterfeit firms, but Shanzhai firms would also open up other routes to serve underserved market segments. As scholars pointed out, Shanzhai firms' development would broaden up as they invest more resources into their respective industries [20]. For example, with Shanzhai firms' capabilities in integrating new technologies or introducing technologies from other fields, or by integrating the needs to serve different market segments, Shanzhai firms are able to open up market opportunities. Furthermore, while most counterfeiters may continuously look for different products to counterfeit, Shanzhai firms actually move between counterfeiting and creating. Even until today, undeniably that late-coming IC designers are still closely following the development of market leaders, however, we can also see latecomers actively involving in creating very genuine products and solutions to the market and serve market niches that leaders may have overlooked. Figure 3 illustrates the role of core competency development in counterfeiters' transition into Shanzhai firms.

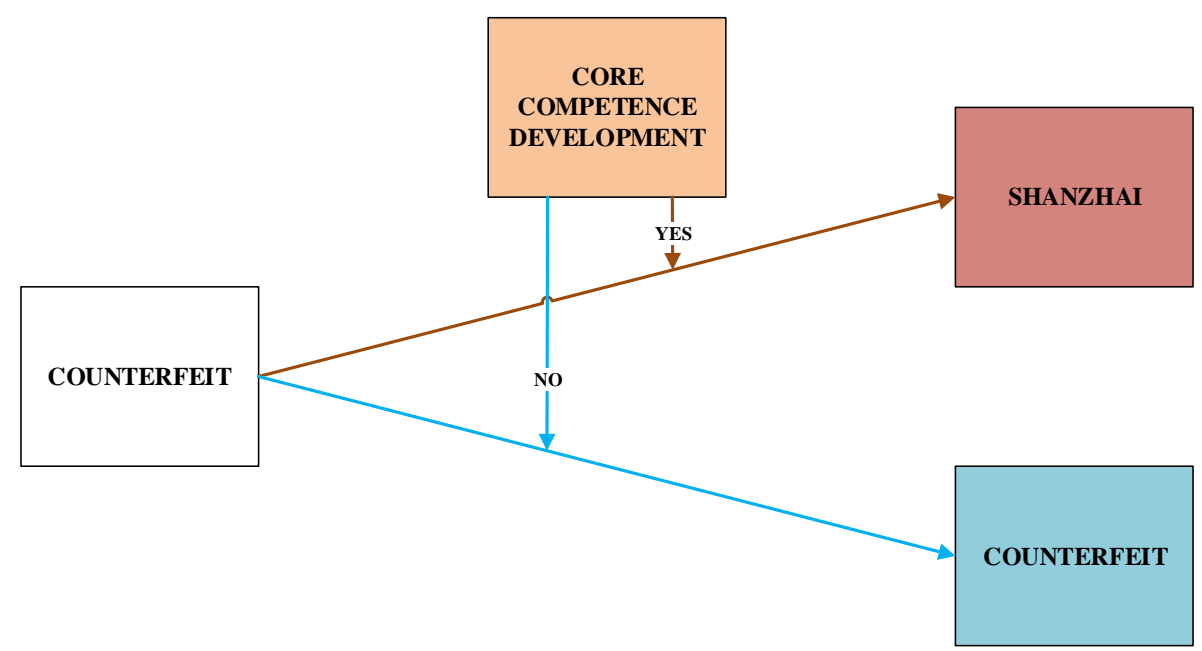

Fig. 3 The role of core competency development in counterfeiters' transition into Shanzhai firms

\section{Inputs for Determination of JMF}

There are many advantages for firms to practice Shanzhai strategies. First, Shanzhai strategies provide firms with a lowered entry barrier into specific industries and in a faster way [20-21]. For some industries such as smartphones or processor chips, it is very expensive for firms to enter the industries in a completely genuine way and also very hard for firms to establish their market positions. For example, while leading firms spend on average between \$100-200 million developing one generation of processor chips [22], this amount would be a huge burden for latecomers to invest at early stages. By first imitating or counterfeiting established firms, Shanzhai firms could accumulate resources early on and then decide whether they would depart from counterfeiting existing technologies and products and begin developing their genuine technologies and products. We see many firms started out making almost identical phones with almost identical technological specifications to leading brands. In recent years, these two brands began making their own technological advancements. For example, a smaller and younger smartphone company from Asia introduced its very first processor chip design, which cost it more than 100 million dollars in research and development [23]. Without the capital resources it accumulated in the past by selling Shanzhai smartphones, it would not be able to achieve this goal.

Second, the innovation path in Shanzhai innovation networks broadens up the deeper the firms are involved in the industry, as opposed to traditional innovative networks where the innovation path would narrow down after a period of time [3]. Scholars argued that the reason behind this finding is that Shanzhai firms would become more flexible in their capabilities to integrate new concepts, new designs, and new technologies into their own products and designs. For example, smartphone designers have been incorporating graphics processing technologies to strengthen the photographic and retouching aspects of smartphones to become specialized in targeted product markets. In a traditional network, however, firms that are specialized in developing cutting-edge technologies will be likely to get stuck into the technological and product paradigms that got them successful in the first place. 
On the other hand, the current literature also points out some liabilities that Shanzhai firms would encounter. First, public perception and brand image on Shanzhai firms and Shanzhai products tend to be more on the negative sides. For example, many people still believe that Shanzhai smartphones are inferior to name-brand smartphones, although third-party testing has shown that some Shanzhai smartphones actually perform better. While many benchmark testings show that Shanzhai smartphones are either at par with or exceeding performances of high-end branding models. Also, many of Shanzhai smartphones now have genuine designs and components. However, public perception would perceive the Shanzhai firm as producing substandard products or well overpriced if selling at competitive prices to high-end branding models.

Second, Shanzhai firms also have a higher risk of being sued. As profitability for branding firms becomes lower, many branding firms blame Shanzhai firms for depriving branding firms' profits. Therefore, branding firms have been raising intensive patenting wars on Shanzhai firms. Many Shanzhai firms have been feeling this heat. For example, many famous smartphones designers started out as Shanzhai firms have been sued by branding firms such as Apple, Qualcomm, and Microsoft over patent infringement. Some products even get banned from selling in the European Union or the United States. Lee et al. [18] pointed out that actions such as counterfeit or imitation commonly observed in Shanzhai firms could become potentially problematic due to the very fine line between being legal or illegal [24].

The related the question to be asked here is: why do we see more Shanzhai activities in emerging economies? Although there are still many liabilities to be Shanzhai firms, we still see Shanzhai strategies flourish in emerging economies. Current literature provides us some clues to the reason why. To date, most firms from emerging economies could be considered as latecomers to their industries. As latecomers, it is crucial for these firms both to utilize the resources they have at hand and to find the fastest way to catch up [20]. First, while many firms from developed economies use emerging economies as their production bases, due to lowered costs and regulations, emerging economies are packed with technologies and capacities to produce cutting-edge products. These technologies and capacities, in turn, become resources for the late-comer firms from emerging economies to work with. Second, using the metaphor from Formula One, when taking over racers in the front, one will first have to closely follow the racer in the front. By closely following the lead racer in the front, there are many advantages such as smoother aerodynamics and knowledge about road conditions. Using similar logic, when latecomers from emerging economies try to follow the development paths of market leaders, latecomers enjoy advantages such as reduced research and development costs and more developed markets [17, 20-21]. Third, as market needs and consumer preferences differ across countries and that most branding firms develop their products based on needs and preferences from their home countries, many market niches from emerging markets remained to be filled [3, 19]. These market niches leave rooms for Shanzhai firms to work with. Shanzhai firms can learn from branding firms, modify branding firms' products according to local needs and preferences, and better serve these underserved markets.

\section{Discussion and Contributions}

Three contributions emerge from this research. First, contributing to the Shanzhai literature, this research is among the first effort attempting to qualitatively examine the emergence and the impact of Shanzhai strategies. We used two case studies to demonstrate how a firm with a background as an OEM firm utilizes Shanzhai strategies to penetrate new markets and to become a renowned brand. We also demonstrated how Shanzhai firms capitalize on modularized technologies to lower entry barriers and to innovate and introduce new products. Second, contributing to the emerging economies literature, this research examines how strategies help late-moving firms from emerging economies tap into mainstream technological developments and even become market-leading firms. Third, contributing to the innovation literature, this research shows how Shanzhai brings about another form of the innovative system. As shown in the previous sections, Shanzhai firms have now evolved from counterfeiting firms into distinctive industries and networks that are able to produce their own competences and innovations. Therefore, Shanzhai could become another innovation system that is distinct from those innovation systems that we are familiar with. 


\section{Future Research}

Shanzhai has been widely utilized and has been effective for some firms not only to gain market positions but to become market leaders. It is safe to say that Shanzhai may be an effective way for latecomers to catch up with leading firms. However, when firms grow stronger and even become leaders, some questions still await to be answered. First, when Shanzhai firms with inferior technologies develop into being more sophisticated, their technological capabilities may be as strong as or even stronger than firms that they used to imitate. For example, many of the applications by Alibaba (Taobao), Tencent (Wechat), and ZTE Corporation are exceeding their counterparts from developed economies. Under this situation, their options to imitate others would be very limited. How will their growth strategies evolve?

Second, when Shanzhai firms become leaders in their industries, what will they do to secure their positions? Compared to leading firms, Shanzhai firms may not be used to defend their intellectual properties [1-2]. When these Shanzhai firms grow stronger, their intellectual properties would increase that there would be firms out there trying to imitate them. How will these Shanzhai firms use and protect their resources? For example, how will Shanzhai firms use (or support) the concepts of open contents versus traditional copyrights?

Third, since public perceptions are likely to link Shanzhai firms more with inferior technologies and brand imitators when Shanzhai firms develop into innovative products, how do Shanzhai firms manage public perceptions and their brand images?

Fourth, if "Shanzhai" refers latecomers from less-developed economies imitating market-leading firms from developed economies, "reverse-Shanzhai" is the imitation behavior by market-leaders on latecomers. This is now becoming a noticeable phenomenon that market-leading firms (such as Facebook from the United States) are now actually "reverse-Shanzhai" on their counterparts from less-developed economies, such as Wechat by Tencent. Facebook's founder and CEO Mark Zuckerberg publically admit Facebook's desire to learn from Wechat and that What's functions and business models could help fuel Facebook's growth [25-27]. With the rise of reverse-Shanzhai, questions yet to be answered raise from both sides. For example, how will the intellectual battlefield transform while both parties are protecting, exploiting, and exploring all at the same time? How will the inter-company relationship become between companies on the two ends of the spectrum?

Finally, although Shanzhai as a term is Chinese in origin, Shanzhai strategies are not limited to firms in emerging economies in general. Numerous firms in today's developed economies such as Britain, Canada, Germany, Japan, and the United States undertook what can be called Shanzhai strategies when their economies were taking off [28]. How these strategies are phased out as IPR protection tightens around the world and as these firms' capabilities to go after high-end markets develop will remain a fascinating area for future research.

\section{Conclusions}

This paper explores how Shanzhai firms emerge. We demonstrated the two contexts that foster Shanzhai firms, and why the Shanzhai phenomenon bloomed from emerging economies and continue to be widespread in emerging markets. Shanzhai firms begin as counterfeiters and some of them have successfully evolved into innovative firms with their own competences that even become global leaders in their respective industries. While the majority of the Shanzhai behaviors are observed on firms from the emerging economies nowadays, firms with more advanced technological capabilities from developed economies have been observed to reverse-Shanzhai on firms from the emerging economies. Therefore, the Shanzhai phenomenon is not specific to the emerging economies, but Shanzhai can and will be a type of growth strategies that companies use to grow their competencies even further.

\section{Conflicts of Interest}

The authors declare no conflict of interest. 


\section{References}

[1] B. Berman, "Strategies to detect and reduce counterfeiting activity," Business Horizons, vol. 51, no. 3, pp. 191-199, 2008.

[2] K. K. Y. Lai and J. L. Zaichkowsky, "Brand imitation: do the Chinese have different views?" Asia Pacific Journal of Management, vol. 16, no. 2, pp. 179-192, August 1999.

[3] K. Rong, Z. Liu, and Y. Shi, "Reshaping the business ecosystem in China: case studies and implications," Journal of Science and Technology Policy in China, vol. 2, no. 2, pp. 171-192, 2011.

[4] M. W. Peng and P. S. Heath, "The growth of the firm in planned economies in transition: institutions, organizations, and strategic choice," Academy of management review, vol. 21, no. 2, pp. 492-528, April 1996.

[5] Y. Hu, "Why Shanzhai mobile phones thrive?" Management \& Technology of SME, vol. 18, pp. 13-114, 2009.

[6] M. Treleven and S. B. Schweikhart, "A risk/benefit analysis of sourcing strategies: single vs. multiple sourcing," Journal of operations management, vol. 7, no. 4, pp. 93-114, December 1988.

[7] T. Staake, F. Thiesse, and E. Fleisch, "Business strategies in the counterfeit market," Journal of Business Research, vol. 65, no. 5, pp. 658-665, 2012.

[8] X. Liu, Y. Xie, and M. Wu, "How latecomers innovate through technology modularization: evidence from China's Shanzhai industry," Innovation, vol. 17, no. 2, pp. 266-280, 2015.

[9] J. Chen, K. G. Chang, and Y. S. Su, "Innovation management: winning competitive advantage in the globe," Taipei, Taiwan: Best-Wise Publishing, 2015.

[10] X. Liu, Y. Wu, and G. Lai, "Strategic transformation of Shanzhai firms: evidence from a Chinese case," International Journal of Technology, Policy and Management, vol. 15, no. 1, pp. 77-94, 2015.

[11] F. Kodama, "Measuring emerging categories of innovation: modularity and business model," Technological Forecasting and Social Change, vol. 71, no. 6, pp. 623-633, 2004.

[12] J. K. Gershenson, G. J. Prasad, and Y. Zhang, "Product modularity: definitions and benefits," Journal of Engineering Design, vol. 14, no. 3, pp. 295-313, 2003.

[13] D. Campagnolo and A. Camuffo, "The concept of modularity in management studies: a literature review," International Journal of Management Reviews, vol. 12, no. 3, pp. 259-283, 2010.

[14] C. Y. Baldwin and K. B. Clark, "Managing in an age of modularity," Managing in the modular age: architectures, networks, and organizations, pp. 84-93, 2003.

[15] R. N. Langlois, "External economies and economic progress: the case of the microcomputer industry," Business history review, vol. 66, no. 1, pp. 1-50, 1992.

[16] J. Zhou, Y. Tong, and J. Li, "Disruptive innovation for the base of the pyramid market: a case study on China's Shanzhai cell phone industry," International Journal of Innovation and Sustainable Development, vol. 6, no. 4, pp. 392-419, 2012.

[17] C. Y. Baldwin and K. B. Clark, "Design rules: the power of modularity," Cambridge, MA: MIT Press, vol. 1, 2000.

[18] C. K. Lee and S. C. Hung, "Institutional entrepreneurship in the informal economy: China's shan- zhai mobile phones," Strategic Entrepreneurship Journal, vol. 8, no. 1, pp. 16-36, 2014.

[19] S. Zhu and Y. Shi, "Shanzhai manufacturing: an alternative innovation phenomenon in China: its value chain and implications for Chinese science and technology policies," Journal of Science and Technology Policy in China, vol. 1, no. 1, pp. 29-49, 2010.

[20] M. A. Schilling and H. K. Steensma, "The use of modular organizational forms: an industry-level analysis," Academy of management journal, vol. 44, no. 6, pp. 1149-1168, 2001.

[21] M. G. Harvey and I. A. Ronkainen, "International counterfeiters-marketing success without the cost and the risk," Columbia Journal of World Business, vol. 20, no. 3, pp. 37-45, 1985.

[22] A. Shilov, "AMD: Development of Zen CPUs is our largest R\&D spending now," https://www.kitguru.net/components/cpu/anton-shilov/amd-development-of-zen-process or-is-our-largest-rd-spending-now/, June 2017.

[23] H. L. Chen, "Xiaomi joins Apple and Samsung, developing its own processors," https://http://www.ithome.com.tw/news/112404, June 2017.

[24] J. Mitra and S. Chunlin, "Innovation, entrepreneurship, and governance: the Shanzhai handset business," ICSB World Conference Proceedings, International Council for Small Business (ICSB), January 2010, p. 1.

[25] S. ADAMS, "Mark Zuckerberg regrets not learning from WeChat sooner," https://radiichina.com/mark-zuckerberg-regrets-not-learning-from-wechat-sooner/, March 2019.

[26] N. Statt and S. Liao, "Facebook wants to be WeChat," https://www.theverge.com/2019/3/8/18256226/facebook-wechat-messaging-zuckerberg-strategy, March 2019. 
[27] I. Deng, "Facebook is changing, and this Chinese app is the model,"

https://www.inkstonenews.com/tech/zuckerberg-regrets-not-learning-wechat-facebook-turns-private-chats/article/30012 18, 2019, March 2019.

[28] M. W. Peng, D. Ahlstrom, S. M. Carraher, and W. S. Shi, “An institution-based view of global IPR history,” Journal of International Business Studies, pp. 1-15, 2017.

Copyright $\odot$ by the authors. Licensee TAETI, Taiwan. This article is an open access article distributed under the terms and conditions of the Creative Commons Attribution (CC BY-NC) license (https://creativecommons.org/licenses/by-nc/4.0/). 